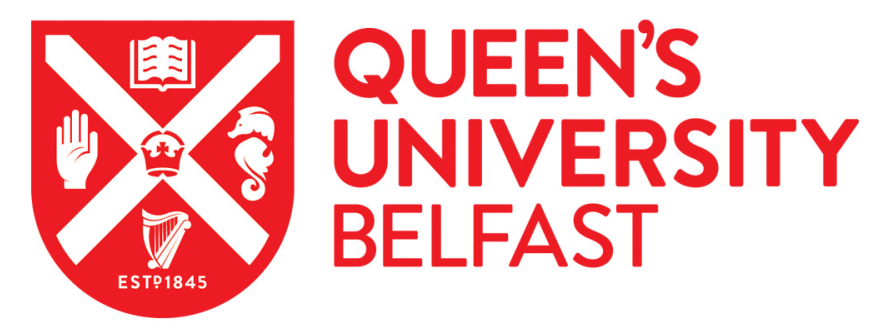

\title{
Potentially inappropriate prescribing in dementia, multi-morbidity and incidence of adverse health outcomes
}

Delgado, J., Jones, L., Bradley, M. C., Allan, L. M., Ballard, C., Clare, L., Fortinsky, R. H., Hughes, C. M., \& Melzer, D. (2020). Potentially inappropriate prescribing in dementia, multi-morbidity and incidence of adverse health outcomes. Age and Ageing, 50(2), 457-464. https://doi.org/10.1093/ageing/afaa147

Published in:

Age and Ageing

Document Version:

Peer reviewed version

Queen's University Belfast - Research Portal:

Link to publication record in Queen's University Belfast Research Portal

Publisher rights

Copyright 2020 OUP. This work is made available online in accordance with the publisher's policies. Please refer to any applicable terms of use of the publisher.

\section{General rights}

Copyright for the publications made accessible via the Queen's University Belfast Research Portal is retained by the author(s) and / or other copyright owners and it is a condition of accessing these publications that users recognise and abide by the legal requirements associated with these rights.

Take down policy

The Research Portal is Queen's institutional repository that provides access to Queen's research output. Every effort has been made to ensure that content in the Research Portal does not infringe any person's rights, or applicable UK laws. If you discover content in the Research Portal that you believe breaches copyright or violates any law, please contact openaccess@qub.ac.uk. 
Potentially inappropriate prescribing in dementia, multimorbidity and incidence of adverse health outcomes 


\section{Key Points}

Individuals with dementia are at risk of potentially inappropriate prescribing (PIP), however, its impact on this population is unknown.

Using primary care records we investigated the effect of PIP in 11,175 individuals with dementia aged over 65 years in 2016 and 43,463 controls matched on age and gender.

Screening-Tool-of-Older-Persons'-Prescriptions V2 defined PIP.

At 73\% prevalence, in individuals with dementia have higher risk of PIP.

PIP was associated with increased risk of all-cause mortality, skin ulcer and pressure sores, falls, anaemia and osteoporosis.

\section{Keywords}

Misprescribing; Beer's; Alzheimer's; vascular dementia; Parkinson's; mortality; delirium; hospitalisation 


\begin{abstract}
Importance: Treatment of dementia in individuals with comorbidities is complex, leading to potentially inappropriate prescribing (PIP). The impact of PIP in this population is unknown.

Objective: Estimate the rate of PIP and its effect on adverse health outcomes (AHO).

Design: Retrospective cohort.

Setting: Primary Care Electronic Health Records linked to hospital discharge data from England.
\end{abstract}

Subjects: 11,175 individuals with dementia aged over 65 years in 2016 and 43,463 age and sex matched controls.

Methods: Screening-Tool-of-Older-Persons'-Prescriptions-V2 defined PIP. Logistic regression tested associations with comorbidities at baseline, and survival analyses risk of incident $\mathrm{AHO}$, adjusted for age, gender, deprivation and 14 comorbidities.

Results: The dementia group had increased risk of PIP (73\% prevalence; odds-ratio 1.92 confidence-interval $\mathrm{Cl} 83-103 \%, \mathrm{p}<0.01$ ) after adjusting for comorbidities. Most frequent PIP criteria were related to anti-cholinergic drugs and therapeutic duplication. Risk of PIP was higher in patients also diagnosed with coronary-heart disease (odds-ratio $2.17 \mathrm{Cl} 1.91$ $2.46 \mathrm{p}<0.01$ ), severe mental illness (odds-ratio $2.09 \mathrm{Cl} 1.62-2.70 \mathrm{p}<0.01$ ); and depression (odds-ratio $1.81 \mathrm{Cl} 1.62-2.01 \mathrm{p}<0.01$ ).

During follow-up (1 year), PIP was associated with increased all-cause mortality (hazardratio $1.14 \mathrm{Cl} 1.02-1.26 \mathrm{p} 0.02$ ), skin ulcer and pressure sores (hazard-ratio $1.66 \mathrm{Cl}$ 1.12-2.46 p 0.01), falls (hazard-ratio $1.37 \mathrm{Cl} 1.15-1.63$ p<0.01), anaemia (hazard-ratio $1.61 \mathrm{Cl} 1.10-2.38$ p 0.02) and osteoporosis (hazard-ratio $1.62 \mathrm{Cl} 1.02-2.57$ p 0.04).

Conclusion: Patients with dementia frequently receive PIPs, and those that do are more likely to experience AHO. These results highlight the need to optimise medication in dementia patients, especially those with comorbidities. 


\section{Background}

Dementia includes irreversible neurological conditions affecting $2-3 \%$ of $65 \mathrm{yr}$ olds, and $30-$ $50 \%$ at 85 plus. ${ }^{1,2}$ These conditions include Alzheimer's dementia (AD), vascular dementia $(\mathrm{VaD})$, Parkinson's dementia, frontotemporal dementia and other rarer forms. ${ }^{3,4}$

Dementia diagnosis frequently occurs with comorbidities, complicating clinical management, 5,6 Individuals diagnosed with dementia are prescribed on average 5 to 10 medications at any one time. ${ }^{7,8}$ High prescription rates place patients at risk of potentially inappropriate prescribing (PIP). ${ }^{9}$ PIP refers to the use of medications when safer alternatives exist. ${ }^{10} \mathrm{PIP}$ is associated with increased risk of adverse drug events, hospitalisation and death, plus reductions in quality of life, and declines in intellectual function. ${ }^{11,12}$ People living with dementia are at risk of PIP and by extension of adverse drug events. ${ }^{1,12}$ However as people living with dementia are often excluded from longitudinal studies evidence of association with outcomes remains limited. Few studies have focussed on the management of multiple conditions in this population. Most recent estimates of PIP prevalence in people living with dementia use outdated criteria, ${ }^{13}$ and studies of the impact of PIP in health outcomes for people living with dementia are unavailable. ${ }^{12}$

We used the Screening Tool of Older Persons' Prescriptions version 2 criteria (STOPP) to estimate prevalence of PIPs among people living with dementia, in UK primary care electronic health records. ${ }^{14}$ We compared this with prevalence in people without recorded dementia, matched on key characteristics. We focus on 3 overarching questions: 1) what is the prevalence of PIP in people living with dementia compared to those without recorded dementia of similar age and gender and accounting for comorbidities? 2) which factors (e.g. comorbidities of dementia) increase the risk of PIP? and 3) is PIP associated with adverse health outcomes for people living with a diagnosis of dementia?

\section{Methods}

The Clinical Practice Research Datalink (CPRD) includes primary care records for patients in the community, nursing or residential settings from 674 UK practices. Records include clinical symptoms, diagnoses and prescriptions recorded during routine clinical practice, and medical test results and participation in health prevention programmes. CPRD is broadly representative of the UK's older population. ${ }^{15,16}$ We used CPRD linked to NHS Hospital 
Episode Statistics (HES) admission data and the UK government's Office for National Statistics (ONS) death certificate register.

\section{Population}

This is a cohort analysis of individuals diagnosed with dementia before or on $1^{\text {st }}$ January 2016 , the study start date (SSD). Individuals included were alive, aged $\geq 65$ years, with records deemed of acceptable research quality (see supplemental material). Diagnosis of dementia were included at the earliest record of a diagnosis code in primary and secondary care records (diagnosis codes in supplemental material - eTable 1). The control group without recorded dementia met the same inclusion criteria. Controls were matched on yearof-birth and gender, with 1 case for 4 controls. Individuals with young-onset dementia or rare forms of dementia including Creutzfeldt-Jakob disease, frontotemporal dementia, and Huntington's disease were excluded as these are distinct presentations with different treatment requirements (eTable 2). ${ }^{17}$ Deprivation status was based on individual postcode, and split into quintiles ${ }^{18}$. Characterization of smoking, drinking habits and body mass index (BMI) described in supplemental material.

\section{Potentially inappropriate prescribing.}

PIP was identified in the lead-in period of 1 year before the SSD. Using prescription records, PIP was defined as the prescription of any combination of drugs deemed potentially harmful by STOPP/START version 2 criteria. ${ }^{14}$ This defines instances of PIP which may increase risks of adverse drug events, applied to a UK and European context. Version 2 of the STOPP criteria specifies errors by commission, better addressing issues of polypharmacy and has a demonstrable association with adverse drug events. ${ }^{19}$ We adapted the Bradley et al. ${ }^{20}$ implementation of STOPP version 1 criteria in CPRD, updating it to version 2 . The comprehensive prescription and clinical data available in CPRD allowed for operationalising 56 of 80 defined criteria.

\section{Multimorbidity and comorbidities of dementia}

14 comorbidities were ascertained: atrial fibrillation, asthma, cancer, coronary heart disease, chronic kidney disease, chronic obstructive pulmonary disease, depression, diabetes mellitus, epilepsy, heart failure, hypertension, hypothyroidism, severe mental illness (psychosis, schizophrenia and bipolar disease causing hallucinations, delusions or catatonia) and stroke. We selected conditions included in the NHS Quality of outcomes 
Framework, an incentive payment programme that improved record keeping. ${ }^{15}$ For chronic conditions, the earliest recorded diagnosis code in primary or secondary health records before the SSD were accepted, and for cancer a diagnosis code recorded in the 5 years before the SSD.

\section{Adverse Health Outcomes}

Adverse health outcomes (AHO) studied included all cause-mortality, hospitalisation (planned and unplanned) and common conditions and syndromes of old age (delirium, anaemia, falls, fractures, incontinence, osteoarthritis, osteoporosis, peptic ulcer, and skin ulcer and pressure sores). Individuals were followed for one year, with AHO recorded as a binary variable at first occurrence during the follow-up period (one year after SSD).

\section{Statistical analysis}

Baseline data analyses produced estimates of PIP prevalence. Prevalence of each STOPP criterion with $95 \%$ confidence intervals (Cls), were calculated. Chi-square analyses tested for differences between dementia and control group. Logistic regression tested associations between PIP in people with dementia and the presence of a diagnosis of 14 chronic conditions. Survival analyses tested the association between PIP and AHO during 1 year of follow-up. Analyses compared individuals with at least one PIP criterion vs none, 3 or more PIP criteria vs none, and in individuals with 3 or more comorbidities. Cox proportional hazards regression model was used for the all-cause mortality, and Fine and Gray competing risk models - all-cause mortality as competing risk - for all other outcomes. ${ }^{21}$ All analyses were adjusted for age (squared), gender and quintiles of multiple deprivation, and diagnoses for 14 chronic conditions. Survival analyses were also adjusted for prior presence of target outcome. For all analyses statistical significance was set at $p$-value $<0.05$. All analyses were conducted using STATA Version 15 (Timberlake Consultants Ltd, London, UK).

Sensitivity analyses were performed to test associations in the subgroup of individuals living in the community. Adjustments for drinking, smoking habits, BMI have the potential for confounding by reverse causation ${ }^{22}$, making it difficult to interpret estimates, thus these were added as a sensitivity analysis.

\section{Declaration of Sources of Funding}

This work was supported by the Alzheimer's Society [grant: 338 (AS-JF-16b-007)]. 


\section{Results}

11,175 individuals diagnosed with dementia before SSD (average age: 84.4 years old, $63.9 \%$ female) were included in analyses, plus 43,463 matched controls (average age: 83.4 years, and $64.6 \%$ female) (Table 1). Cases were well matched with $99.1 \%$ matched with 3 or 4 controls, and the remainder with 1 or 2 controls.

A total of 8,211 individuals with dementia had at least one PIP according to the STOPP version 2 criteria (Table 2). Prevalence of PIP was higher in individuals diagnosed with dementia (73.5\%) compared to individuals of similar age and gender without a record of dementia (57.0\%). This difference between groups was statistically significant (OR) 1.92, 95\% confidence interval $(\mathrm{Cl}) 1.83-2.03 p<0.01$ ) after adjusting for adjusting for age (squared), gender, quintiles of deprivation, and diagnosis of 14 chronic comorbidities. The increased PIP risk remained in individuals living in the community $(\mathrm{OR} 1.86 \mathrm{Cl}$ 1.76-1.96 p $<0.01)$.

In individuals with dementia, 11 out of the 56 criteria had prevalence greater than $5 \%$ (eTable 3), with the most common being: 1) anticholinergics/antimuscarinics in patients with delirium or dementia (46.1\%); 2 ) any duplicate drug class prescription (optimisation of monotherapy within a single drug class) (31.5\%); 3) non-Steroidal Anti-Inflammatory (NSAID) with severe hypertension or severe heart failure (22.5\%).

\section{Prevalence of PIP in dementia by comorbidities}

In the dementia group prevalence of PIP increased with the number of comorbidities (0: 39.3\%, 1-2: 61.9\%, 3-6: 82.1\%, 7 or more PIP: 93.5\%). Comorbidities associated with higher PIP prevalence were: coronary heart disease (OR $2.17 \mathrm{CI} 1.91-2.46 \mathrm{p}<0.01)$; severe mental illness (OR 2.09 Cl1.62-2.70 p <0.01); depression (OR 1.81 Cl 1.62-2.01 p<0.01); chronic obstructive pulmonary disease (OR $1.80 \mathrm{Cl} 1.51-2.14 \mathrm{p}<0.01$ ); and hypertension (OR 1.67 Cl1.52-1.84 $p<0.01$ ) (Table 3). Conditions not associated with increased risk of PIP were epilepsy, hypothyroidism, a recent history of cancer, and asthma.

\section{Association of PIP and incidence of adverse health outcomes}

In the dementia group having at least one instance of PIP in the year prior to SSD was associated with incidence of all-cause mortality (hazard ratio (HR) $1.14 \mathrm{Cl} 1.02-1.26 \mathrm{p} \mathrm{0.02}$ ), skin ulcer and pressure sores (HR 1.66 Cl 1.12-2.46 p 0.01), falls (HR $1.37 \mathrm{Cl} 1.15-1.63 p$ 
$<0.01$ ), anaemia (HR $1.61 \mathrm{Cl} 1.10-2.38$ p 0.02) and osteoporosis (HR $1.62 \mathrm{Cl} 1.02-2.57 \mathrm{p} \mathrm{0.04)}$ (Table 4). In individuals with 3 or more PIP, additional statistically significant associations were identified for at least one hospitalisation in the following year (HR 1.15 Cl 1.05-1.25 p $<0.01$ ), delirium (HR $1.36 \mathrm{Cl} 1.06-1.74$ p 0.02) and incontinence (HR $1.34 \mathrm{Cl} 1.01-1.78$ p 0.04). Other tested outcomes such as fractures and peptic ulcer were not associated with instances of PIP (Table 4). Lastly, in individuals with 3 or more PIP and 3 or more comorbidities we found similar associations with $\mathrm{AHO}$, although for all-cause mortality (HR $1.08 \mathrm{Cl} 0.94-1.24 \mathrm{p} 0.26$ ) and incontinence ( $\mathrm{HR} 1.25 \mathrm{Cl} \mathrm{0.90-1.74} \mathrm{p} \mathrm{0.18)} \mathrm{the} \mathrm{associations}$ were not significant. In a sensitivity analysis on a sub-sample of individuals living in the community, associations were little changed (eTable 4) although for all-cause mortality narrowly missed statistical significance (HR $1.11 \mathrm{Cl} 0.99-1.24 \mathrm{p} 0.07)$. Sensitivity analyses with additional adjustments for drinking, smoking, BMI and years since dementia diagnosis demonstrated similar results (eTable 5), but the association with incontinence narrowly missed significance (OR 1.29 CI95 0.97-1.72 p. 0.07).

\section{Discussion}

This study provides estimates for PIP prevalence in a large, broadly representative sample of UK primary care patients living with a diagnosis of dementia, in 2016. PIP prevalence with dementia in the year before the 01 January 2016 was 73.4\%; this is higher than previous comparable estimates, which ranged from $13.9 \%$ to $64.5 \%$ in different settings. Remarkably, people with a diagnosis of dementia were $83 \%$ to $103 \%$ more likely to have a recorded PIP than individuals of similar age and gender without a record of dementia, after accounting for 14 comorbidities and socio-economic deprivation. This is similar to previous findings of higher prevalence of PIP in people living with dementia. ${ }^{23,24}$

Importantly, this study establishes for the first time an association between presence of PIP and increased risk of AHO for people living with dementia. Individuals with one or more PIP had increased mortality, plus increased rates of skin ulcer and pressure sores, falls and anaemia: higher risks of $\mathrm{AHO}$ s were present in those with $\geq 3 \mathrm{PIP}$, with additional association with hospital admissions, delirium and incontinence. The results did not meaningfully change when focussing on those living in the community or when adjusting for lifestyle, body composition and years living with dementia (eTable 4 \& 5). Studies investigating PIP in people with dementia have mainly focused on the prevalence and risk factors of PIP, ${ }^{24}$ while 
studies of PIP impacts on mortality and morbidity in this group are unavailable. ${ }^{12}$ Our study demonstrates that PIP is associated with a real increase in health risks to people living with dementia, further supporting the case for improving medication management in this group.

Medical conditions in older individuals with dementia are commonly managed pharmacologically, and optimisation of medication remains a challenge. ${ }^{25}$ Management of co-morbidities is likely a contributor to the high prevalence of PIP in people living with dementia. The two most frequent PIP criteria include: therapeutic duplication, which is closely associated with treatment of multiple conditions, and has been described as "caused by poor communication between different physicians"; ${ }^{26}$ and prescription of anticholinergic/antimuscarinic drugs in patients with delirium or dementia, drugs commonly used to treat some dementia symptoms (i.e. sedatives) but also to treat co-morbidities of dementia, including cardiovascular disease (i.e. anti-arrhythmic) and incontinence (i.e. antimuscarinic drugs). ${ }^{27}$

Evidence to guide management of chronic conditions (e.g. diabetes) in people with dementia remains limited. ${ }^{25} \mathrm{~A}$ recent review of treatment for dementia co-morbidities identified six studies, covering depression, osteoporosis, diabetes and cardiovascular disease, and only one assessed the impact of treatment on clinical outcomes. ${ }^{25}$ This lack of evidence is particularly problematic for patients within the later stages of dementia when treatment targets are likely to change.

Further research into prescribing practices in dementia remains necessary. Studies are needed on prescribing challenges, management of trade-offs between therapeutic benefits and adverse outcomes, especially for advanced stages of dementia. Studies should also investigate if varying modes of access to healthcare professionals can improve prescribing. Meanwhile, improving coordination between primary care and secondary care services may contribute to reducing PIP. ${ }^{28,29}$ Also, medication reviews, including reviews based on STOPP/START can reduce PIP and adverse drug events. ${ }^{30}$ Medication reviews could focus on comorbidities associated with the highest PIP risk (e.g. coronary heart disease; depression) or on the most common PIP criteria (e.g. prescription of anti-cholinergic drugs to people diagnosed with dementia and therapeutic duplication). 


\section{Strengths and weaknesses}

This is one of the largest studies of PIP prevalence in dementia. The 'real world' clinical data available in CPRD includes both primary and secondary care records, plus accurate prescription and dosage information, providing robust data and allowing comprehensive assessment of PIP. ${ }^{15}$

STOPP criteria were initially designed for implementation by health care services based on the patient's complete medical history. ${ }^{14}$ Despite comprehensive access to patient medical records there are some barriers to producing a complete picture of prescription practices in primary care. Information available was only sufficient to implement 56 of 80 criteria. Information is not available for over-the-counter medication. It is impossible to ascertain medication adherence from the electronic medical records analysed. Additional limitations include possible undiagnosed dementia amongst controls, however this should result in estimates with smaller effect sizes. Also, information available did not allow for accurately characterising dementia severity, or analysis of how this affects prescribing decisions and outcomes. Nonetheless, results produced are consistent with findings from previous studies based on the STOPP version 2 criteria, suggesting correct implementation of the criteria. ${ }^{23}$ Our observational design does not provide proof of a causal relationship between PIP and incidence of AHO; however the associations are in line with findings from previous applications of the STOPP criteria to the general population. ${ }^{19}$ Additional work is necessary to test relationships between PIP and AHO in this population.

\section{Conclusions}

PIP is common in primary care patients living with dementia, and these individuals have double the risk of PIP compared to individuals of similar age and gender without a record of dementia after accounting for 14 chronic conditions. Risk of PIP was exacerbated by multimorbidity, with the most common PIP involving drugs with anti-cholinergic effects and therapeutic duplication. This study also showed that prescription of PIP is associated with higher rates of Adverse Health Outcomes. This observational evidence highlights the need for more research with the goal of optimising medication in this patient group and improve clinical outcomes. 


\section{Acknowledgments}

Ethical and scientific approval

The CPRD has been granted Multiple Research Ethics Committee approval (05/MRE04/87)

for purely observational studies, with external data linkages including HES and ONS

mortality data. The work of CPRD is also covered by National Information Governance Board

for Health and Social Care - Ethics and Confidentiality Committee (NIGB-ECC) approval ECC 5-05 (a) 2012. This study was approved by the Independent Scientific Advisory Committee (ISAC) for the Medicines and Healthcare products Regulatory Agency (MHRA), under ISAC protocol number 106903R.

Declaration of interests, financial or personal relationships

No relevant interests, financial or personal relationships declared. 


\section{REFERENCES}

1. Meloni E, Vetrano DL, Bernabei R, Onder G. Appropriateness of pharmacological treatment in older people with dementia. Ital J Med. 2015;9(3):212-216. doi:10.4081/itjm.2015.539

2. Swanson KA, Carnahan RM. Dementia and comorbidities: An overview of diagnosis and management. J Pharm Pract. 2007;20(4):296-317.

doi:10.1177/0897190007308594

3. Langa KM, Foster NL, Larson EB. Mixed Dementia. Jama. 2004;292(23):2901. doi:10.1001/jama.292.23.2901

4. Knapp M, Guerchet M, McCrone M, et al. Dementia UK: Update.; 2014.

5. Poublador-Plou B, Calderon-Larranaga A, Marta-Moreno J, et al. Comorbidity of dementia: a cross-sectional study of primary care older patients. BMC Psychiatry. 2014;14(84):1:8. doi:10.1186/1471-244X-14-84

6. Callahan C, Schubert C. Dementia: The complexities of comorbidity in dementia. Nat Rev Neurol. 2014;10(4):184-186. doi:10.1038/nrneurol.2014.46

7. Kanagaratnam L, Mahmoudi R, Novella JL, Jolly D, Drame M, Trenque T. Adverse drug reactions in elderly subjects hospitalized in a specialized dementia management unit. Drugs and Aging. 2014;31(10):769-776. doi:10.1007/s40266-014-0206-0

8. Barry HE, Cooper JA, Ryan C, et al. Potentially Inappropriate Prescribing Among People with Dementia in Primary Care: A Retrospective Cross-Sectional Study Using the Enhanced Prescribing Database. J Alzheimers Dis. 2016;Preprint(Preprint):1-11. doi:10.3233/JAD-151177

9. Moriarty F, Hardy C, Bennett K, Smith SM, Fahey T. Trends and interaction of polypharmacy and potentially inappropriate prescribing in primary care over 15 years in Ireland: A repeated cross-sectional study. BMJ Open. 2015;5(9):1-8. doi:10.1136/bmjopen-2015-008656

10. Hamilton HJ, Gallagher PF, O'Mahony D. Inappropriate prescribing and adverse drug events in older people. BMC Geriatr. 2009;9(1):1-4. doi:10.1186/1471-2318-9-5 
11. Patel T, Slonim K, Lee L. Use of potentially inappropriate medications among ambulatory home-dwelling elderly patients with dementia: A review of the literature. Can Pharm J / Rev des Pharm du Canada. 2017;150(3):169-183.

doi:10.1177/1715163517701770

12. Parsons C. Polypharmacy and inappropriate medication use in patients with dementia: an underresearched problem. Ther Adv Drug Saf. 2017;8(1):31-46. doi:10.1177/2042098616670798

13. Parsons $\mathrm{C}$, Johnston $\mathrm{S}$, Mathie $\mathrm{E}$, et al. Potentially inappropriate prescribing in older people with dementia in care homes: a retrospective analysis. Drugs and Aging. 2012;29(2):143-155. doi:10.2165/11598560-000000000-00000

14. O'mahony D, O'sullivan D, Byrne S, O'connor MN, Ryan C, Gallagher P. STOPP/START criteria for potentially inappropriate prescribing in older people: Version 2. Age Ageing. 2015;44(2):213-218. doi:10.1093/ageing/afu145

15. Herrett E, Gallagher AM, Bhaskaran K, et al. Data Resource Profile: Clinical Practice Research Datalink (CPRD). Int J Epidemiol. 2015;44(3):827-836. doi:10.1093/ije/dyv098

16. Herrett E, Thomas SL, Schoonen WM, Smeeth L, Hall AJ. Validation and validity of diagnoses in the General Practice Research Database: A systematic review. Br J Clin Pharmacol. 2010;69(1):4-14. doi:10.1111/j.1365-2125.2009.03537.x

17. Mahant N, McCusker EA, Byth K, Graham S. Huntington's disease. Neurology. 2003;61(8):1085-1092.

18. Lad M. The English Indices of Deprivation 2010. London, UK; 2010. doi:ISBN 9781409829249

19. Wallace E, McDowell R, Bennett K, Fahey T, Smith SM. Impact of Potentially Inappropriate Prescribing on Adverse Drug Events, Health Related Quality of Life and Emergency Hospital Attendance in Older People Attending General Practice: A Prospective Cohort Study. Journals Gerontol Ser A Biol Sci Med Sci. 2016;00(00):glw140. doi:10.1093/gerona/glw140 
20. Bradley MC, Motterlini N, Padmanabhan S, et al. Potentially inappropriate prescribing among older people in the United Kingdom. BMC Geriatr. 2014;14(1):1-9. doi:10.1186/1471-2318-14-72

21. Fine J, Gray R. A Proportional Hazards Model for the Subdistribution of a Competing Risk. J Am Stat Assoc. 1999;94(446):496-509. doi:10.2307/2670170

22. Bowman K, Atkins JL, Delgado J, et al. Central adiposity and the overweight risk paradox in aging: Follow-up of 130,473 UK Biobank participants. Am J Clin Nutr. 2017;106(1). doi:10.3945/ajcn.116.147157

23. Kristensen RU, Nørgaard A, Jensen-Dahm C, Gasse C, Wimberley T, Waldemar G. Polypharmacy and Potentially Inappropriate Medication in People with Dementia: A Nationwide Study. J Alzheimer's Dis. 2018;63(1):383-394. doi:10.3233/JAD-170905

24. Eshetie T, Nguyen T, Gillam M, Ellett LK. Potentially inappropriate prescribing before and after initiation of anti-dementia medicines: An australian population-based study. Geriatr Gerontol In. 2019;Epub ahead. doi:10.1111/ggi.13686

25. Page A, Etherton-Beer C, Seubert $L$, et al. Medication use to manage comorbidities for people with dementia: a systematic review. J Pharm Pract Res. 2018;48(4):356367. doi:10.1002/jppr.1403

26. Meredith S, Feldman PH, Frey D, et al. Possible medication errors in home healthcare patients. J Am Geriatr Soc. 2001;49(6):719-724. doi:10.1046/j.15325415.2001.49147.x

27. Richardson K, Fox C, Maidment I, et al. Anticholinergic drugs and risk of dementia : case-control study. Br Med J. 2018;360(k1315):1-12. doi:10.1136/bmj.k1315

28. DeRhodes KH. The Dangers of Ignoring the Beers Criteria -The Prescribing Cascade. JAMA Intern Med. 2019;Published. doi:10.1001/jamainternmed.2019.1288

29. Avery AJ, Coleman JJ. Tackling potentially inappropriate prescribing. BMJ. 2018;363(November):k4688. doi:10.1136/bmj.k4688

30. Gray SL, Hart LA, Perera S, Semla TP, Schmader KE, Hanlon JT. Meta-analysis of Interventions to Reduce Adverse Drug Reactions in Older Adults. J Am Geriatr Soc. 
2018;66(2):282-288. doi:10.1111/jgs.15195 


\section{Tables and Figures}

Table 1: Baseline characteristics - with diagnosis of dementia vs no-diagnosis

\begin{tabular}{|c|c|c|c|}
\hline & Dementia & No dementia & Total \\
\hline Number & 11,175 & 43,463 & 54,638 \\
\hline Age (sd) & $84.6(7.4)$ & $84.3(7.3)$ & $84.4(7.3)$ \\
\hline Female (\%) & $7,328(65.6)$ & $28,077(64.6)$ & $35,405(64.8)$ \\
\hline \multicolumn{4}{|c|}{ Quintiles of index of multiple deprivation (\%) } \\
\hline 1 (Lowest) & 21.9 & 26.3 & 25.8 \\
\hline 2 & 20.9 & 22.7 & 22.4 \\
\hline 3 & 24.4 & 22.3 & 22.7 \\
\hline 4 & 19.6 & 17.0 & 17.6 \\
\hline 5 (Highest) & 13.2 & 11.7 & 12.0 \\
\hline \multicolumn{4}{|l|}{ Body Mass Index (\%) } \\
\hline Underweight & 6.4 & 2.8 & \\
\hline Normal & 32.9 & 29.1 & \\
\hline Pre-obesity & 22.7 & 28.3 & \\
\hline Obese 1 & 8.6 & 11.8 & \\
\hline Obese $2 \& 3$ & 3.1 & 4.5 & \\
\hline missing & 26.3 & 23.6 & \\
\hline \multicolumn{4}{|l|}{ Smoking (\%) } \\
\hline Not smoker & 50.1 & 48.0 & \\
\hline Ex smoke & 27.8 & 30.1 & \\
\hline Currently not smoking & 2.0 & 1.0 & \\
\hline Smoking & 7.4 & 7.8 & \\
\hline missing & 12.7 & 13.2 & \\
\hline \multicolumn{4}{|l|}{ Drinking (\%) } \\
\hline Not drinker & 24.3 & 18.1 & \\
\hline Ex-drinker & 7.3 & 3.4 & \\
\hline Drinker & 15.7 & 20.4 & \\
\hline
\end{tabular}




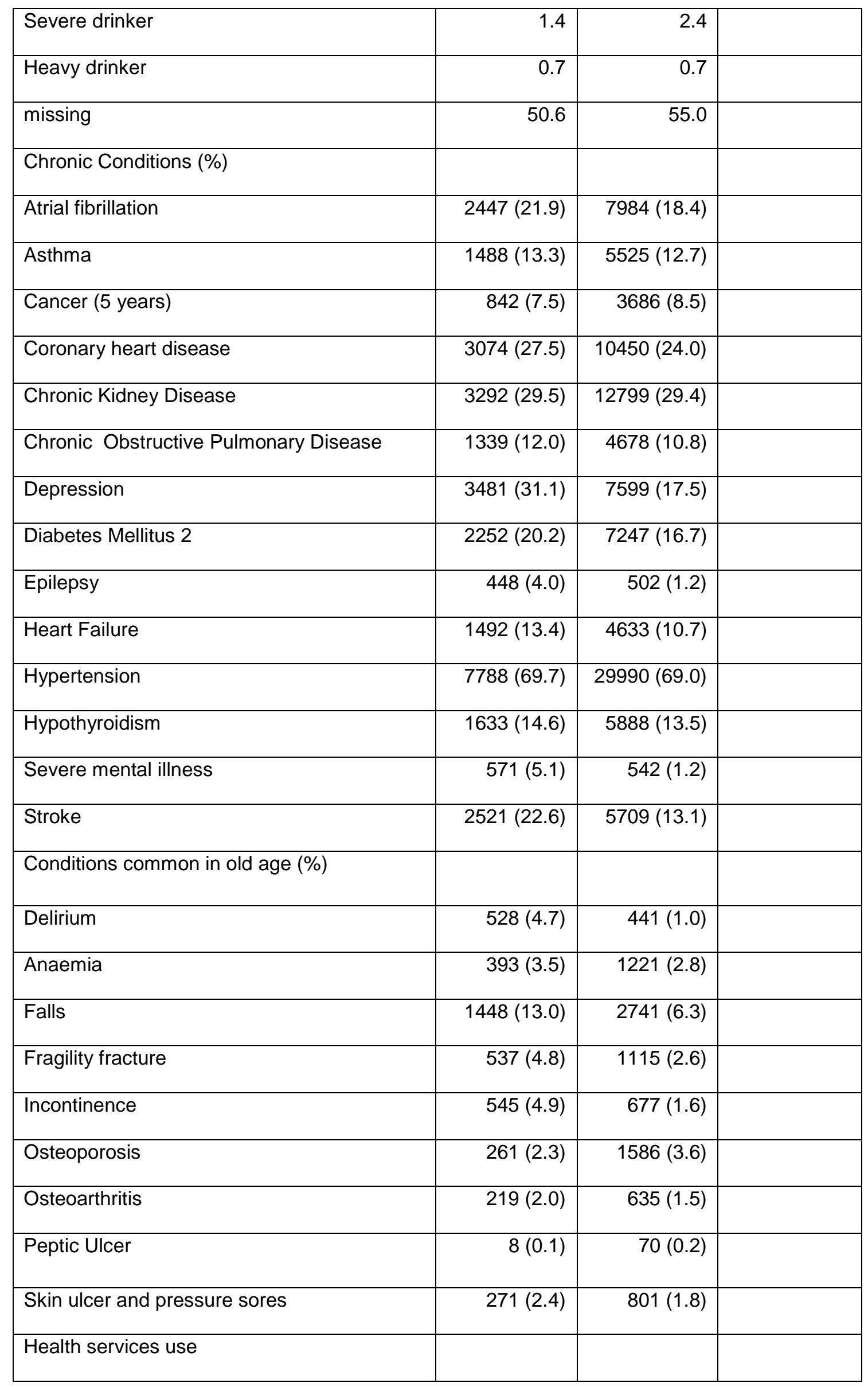




\begin{tabular}{|l|r|r|r|}
\hline Visits to GP previous year - average(SD) & $8.5(6.5)$ & $6.1(5.3)$ & \\
\hline Seen by GP at a nursing home (\%) & $1,075(9.6)$ & $439(1.0)$ & \\
\hline Referral to geriatric services (\%) & $572(5.1)$ & $593(1.4)$ & \\
\hline Referral to cardiology services (\%) & $154(1.4)$ & $1173(2.7)$ & \\
\hline
\end{tabular}


Table 2: Prevalence of PIP in patients with dementia versus without recorded dementia - total and by chapter of STOPP V2 Criteria.

\begin{tabular}{|c|c|c|c|c|c|c|}
\hline \multirow[b]{2}{*}{ STOPP criteria (excluding dementia rules) } & \multicolumn{2}{|c|}{ Dementia } & \multicolumn{2}{|c|}{ No dementia } & \multirow[b]{2}{*}{ diff } & \multirow[b]{2}{*}{$\mathrm{p}^{*}$} \\
\hline & \# & $\%$ & \# & $\%$ & & \\
\hline At least 1 PIP & 8211 & 73.5 & 24766 & 57.0 & 16.49 & $<0.01$ \\
\hline A: Indication of medication & 3520 & 31.5 & 11638 & 26.8 & 4.72 & $<0.01$ \\
\hline B: Cardiovascular System & 1103 & 9.9 & 3925 & 9.0 & 0.84 & 0.01 \\
\hline C: Antiplatelet/Anticoagulant Drugs & 328 & 2.9 & 1325 & 3.1 & -0.11 & 0.53 \\
\hline D: Central Nervous System and Psychotropic Drugs & 5134 & 45.9 & 3519 & 8.1 & 37.85 & $<0.01$ \\
\hline E: Renal System. & 1547 & 13.8 & 5903 & 13.6 & 0.26 & 0.47 \\
\hline F: Gastrointestinal System & 2336 & 20.9 & 6774 & 15.6 & 5.32 & $<0.01$ \\
\hline G: Respiratory System & 84 & 0.8 & 307 & 0.7 & 0.05 & 0.61 \\
\hline H: Musculoskeletal System & 3116 & 27.9 & 12025 & 27.7 & 0.22 & 0.65 \\
\hline I: Urogenital System & 738 & 6.6 & 594 & 1.4 & 5.24 & $<0.01$ \\
\hline J. Endocrine System & 604 & 5.4 & 2447 & 5.6 & -0.23 & 0.36 \\
\hline $\begin{array}{l}\text { K: Drugs that predictably increase the risk of falls in } \\
\text { older people }\end{array}$ & 304 & 2.7 & 311 & 0.7 & 2.00 & $<0.01$ \\
\hline L: Analgesic Drugs & 606 & 5.4 & 2395 & 5.5 & -0.09 & 0.72 \\
\hline N: Antimuscarinic/Anticholinergic Drug Burden & 1559 & 14.0 & 2335 & 5.4 & 8.58 & $<0.01$ \\
\hline
\end{tabular}

${ }^{*}$ p-value produced using $\mathrm{chi}^{2}$ analysis. 
Table 3: Association between diagnosis with a chronic condition and risk of PIP in individuals diagnosed with dementia

\begin{tabular}{|c|c|c|c|c|c|c|}
\hline & \multicolumn{3}{|c|}{ Base adjustment* } & \multicolumn{3}{|c|}{$\begin{array}{l}\text { Base adjustment* + } \\
\text { comorbidities }^{*}\end{array}$} \\
\hline & OR & $\mathrm{Cl} \%$ & $\mathrm{p}$ & OR & $\mathrm{Cl} \%$ & $\mathrm{p}$ \\
\hline Atrial fibrillation & 2.32 & $2.05-2.61$ & $<0.01$ & 1.61 & $1.41-1.83$ & $<0.01$ \\
\hline Asthma & 1.66 & $1.45-1.90$ & $<0.01$ & 1.18 & $1.01-1.37$ & 0.04 \\
\hline Cancer (5 years) & 1.36 & $1.14-1.61$ & $<0.01$ & 1.19 & $0.99-1.43$ & 0.06 \\
\hline Coronary heart disease & 3.26 & $2.90-3.67$ & $<0.01$ & 2.17 & $1.91-2.46$ & $<0.01$ \\
\hline Chronic Kidney Disease & 2.23 & $2.01-2.48$ & $<0.01$ & 1.66 & $1.48-1.85$ & $<0.01$ \\
\hline Chronic Obstructive Pulmonary Disease & 2.38 & $2.02-2.79$ & $<0.01$ & 1.80 & $1.51-2.14$ & $<0.01$ \\
\hline Depression & 2.13 & $1.92-2.35$ & $<0.01$ & 1.81 & $1.62-2.01$ & $<0.01$ \\
\hline Diabetes Mellitus 2 & 2.23 & $1.97-2.52$ & $<0.01$ & 1.58 & $1.38-1.80$ & $<0.01$ \\
\hline Epilepsy & 1.26 & $1.0-1.58$ & 0.05 & 0.93 & $0.73-1.20$ & 0.59 \\
\hline Heart Failure & 2.53 & $2.17-2.96$ & $<0.01$ & 1.22 & $1.02-1.44$ & 0.03 \\
\hline Hypertension & 2.49 & $2.27-2.72$ & $<0.01$ & 1.67 & $1.52-1.84$ & $<0.01$ \\
\hline Hypothyroidism & 1.31 & $1.16-1.48$ & $<0.01$ & 1.04 & $0.91-1.19$ & 0.54 \\
\hline Severe mental illness & 2.41 & $1.88-3.07$ & $<0.01$ & 2.09 & $1.62-2.70$ & $<0.01$ \\
\hline Stroke & 1.81 & $1.62-2.03$ & $<0.01$ & 1.34 & $1.19-1.51$ & $<0.01$ \\
\hline
\end{tabular}

* Base adjustment: age (squared), gender and quintiles of multiple deprivation.

$¥$ Conditions: atrial fibrillation, asthma, cancer (5 years), coronary heart disease, chronic kidney disease (stage 3 to 5), chronic obstructive pulmonary disease, depression, diabetes mellitus, epilepsy, heart failure, hypertension, hypothyroidism, severe mental illness and stroke, 
Table 4: Association between PIP and incidence of adverse health outcomes in the follow-up period, in individuals diagnosed with dementia.

\begin{tabular}{|l|c|c|c|c|c|c|c|c|c|}
\hline & \multicolumn{3}{|c|}{ Any one PIM criteria } & \multicolumn{3}{l}{3 3 or more PIM criteria } & \multicolumn{3}{l}{3 or more conditions } \\
\hline & $\mathrm{HR}^{\star}$ & $\mathrm{Cl} \%$ & $\mathrm{p}$ & $\mathrm{HR}$ & $\mathrm{Cl} \%$ & $\mathrm{p}$ & $\mathrm{HR}^{*}$ & $\mathrm{Cl} \%$ & $\mathrm{p}$ \\
\hline All-cause mortality & 1.14 & $1.02-1.26$ & 0.02 & 1.17 & $1.04-1.32$ & 0.01 & 1.08 & $0.94-1.24$ & 0.26 \\
\hline Hospitalisation & 1.05 & $0.97-1.13$ & 0.23 & 1.15 & $1.05-1.25$ & $<0.01$ & 1.10 & $1.0-1.22$ & 0.05 \\
\hline Delirium & 1.23 & $0.99-1.53$ & 0.06 & 1.36 & $1.06-1.74$ & 0.02 & 1.36 & $1.02-1.81$ & 0.03 \\
\hline Anaemia & 1.61 & $1.10-2.38$ & 0.02 & 1.74 & $1.12-2.71$ & 0.01 & 1.67 & $1.04-2.68$ & 0.03 \\
\hline Fall & 1.37 & $1.15-1.63$ & $<0.01$ & 1.51 & $1.23-1.85$ & $<0.01$ & 1.43 & $1.14-1.81$ & $<0.01$ \\
\hline Fracture & 0.92 & $0.70-1.19$ & 0.51 & 0.92 & $0.67-1.26$ & 0.60 & 0.84 & $0.58-1.21$ & 0.34 \\
\hline Incontinence & 1.22 & $0.95-1.56$ & 0.12 & 1.34 & $1.01-1.78$ & 0.04 & 1.25 & $0.90-1.74$ & 0.18 \\
\hline Osteoarthritis & 1.58 & $1.01-2.49$ & 0.05 & 1.49 & $.89-2.49$ & 0.13 & 1.27 & $0.74-2.19$ & 0.38 \\
\hline Osteoporosis & 1.62 & $1.02-2.57$ & 0.04 & 1.73 & $1.05-2.86$ & 0.03 & 2.58 & $1.20-5.57$ & 0.02 \\
\hline Peptic Ulcer & 0.38 & $0.08-1.74$ & 0.21 & 0.33 & $.06-1.80$ & 0.20 & 0.32 & $0.07-1.45$ & 0.14 \\
\hline Bed ulcer and pressure & 1.66 & $1.12-2.46$ & 0.01 & 1.87 & $1.21-2.90$ & 0.01 & 1.72 & $1.06-2.81$ & 0.03 \\
\hline sores & & & & & & & & & \\
\hline
\end{tabular}

All analyses were adjusted for age, gender, the diagnosis of 14 chronic conditions and prior incidence of outcome (except for all-cause mortality)

*Hazard ratios provided for all-cause mortality and sub-hazard ratios for other outcomes. 